\title{
riginal Article
}

\section{Association between lifestyle satisfaction and tendency to behavioral change with health related quality of life among 40 years old and over in (North of Iran) Mazandaran}

* Rezaali Mohammadpour

Department of Biostatistics, Health Faculty, Health Sciences Research Center, Mazandaran University of Medical Sciences, Sari, Iran.

*mohammadpour2002@yahoo.com

\section{Abstract}

Background and purpose: Health related quality of life (HQOL) has different dimensions and many factors affect it. The aim of this study was to investigate the association between lifestyle satisfaction and health- related quality of life in the population aged 40 year old and over. The question is, if there is not lifestyle satisfaction, how should be the pattern of tendency to behavioral changes?

Materials and methods: This is a cross-sectional study. The statistical population is the inhabitants aged40 and over in Mazandaran province. One thousand and two hundred twenty five subjects by stratification and clustering random sampling were selected. The data were collected by face-to-face interview using the Persian version of the Short Form Health survey (SF-36). SF-36 is a standard questionnaire and Persian translation is valid and reliable. Lifestyle variable assessment includes smoking, physical activity, nutritional status, exercise and stress. Lifestyle satisfaction, tendency to behavioral change and demographic variables were assessed by separate questionnaire. The statistical analysis was performed by T-test and ANOVA by SPSS.

Results: All health related quality of life components had meaningful relationship with lifestyle satisfaction. The mean of all the components of SF-36 measurements for those who had high lifestyle satisfaction were higher than the others $(\mathrm{p}<0.001)$.The highest amount of tendency to behavioral change was seen in nutritional status, exercise, stress control and smoking habits.

Conclusion: According to the results, for promoting physical and mental health, lifestyle satisfaction must be increased. Nutrition, exercise, and giving up smoking are of great importance in physical health promotion.

I* Mohammadpour RA. Association between lifestyle satisfaction and tendency to behavioral change with health related quality of life among 40 years old and over in (North of Iran) Mazandaran. IJHS 2013; 1(I): 31-35] http://jhs.mazums.ac.ir

Key words: Lifestyle, Quality of Life, SF-36, Iran 


\section{Introduction}

Health related quality of life is a concept denoting an individual's response to the physical, mental and social impact of disease on everyday life and the SF-36 health survey is a multipurpose, short-form health survey (1). Quality of life encompasses numerous factors and dimensions. An individual's lifestyle is affected by his/her values, attitudes, habits and behaviors. Unhealthy behaviors are associated with lower quality of life. Smoking, poor physical activity, inappropriate nutrition, and stress are among such behaviors (2). Modifying lifestyle may improve health related quality of life (3). People who are not satisfied with their lifestyle need to decide for change and feel the necessity of improving their quality of life through modifications (4). Satisfaction with lifestyle and health related quality of life may have a mutual impact on one another. If a person is unsatisfied with their lifestyle and cannot modify it, it will affect the mental health of themselves and their families, thus reducing quality of life. Alternatively, a person may attribute his poor quality of life to his own lifestyle and personal behaviors, and as they cannot change their behavior, their physical and mental health will suffer. This quality of life, influenced by different factors, is a major factor for use of healthcare services. In addition, quality of life creates a positive or negative attitude in using services and satisfaction with them (5). Therefore, it is necessary to investigate the correlation between satisfaction with lifestyle and quality of life. Studies in Mazandaran province and elsewhere in Iran have indicated that many lifestyles in different classes are not healthy in terms of BMI, nutritional status, physical exercise, and tobacco or drug use, and require education and interventions (6-8). Thus, here we evaluate the inclination for modifying behaviors and satisfaction with lifestyle and its relationship with quality of life in individuals aged above 40 years in Mazandaran province.

\section{Materials and Methods}

This is a cross-sectional study. Our study population consisted of all individuals aged above 40 years residing in urban and rural areas of Mazandaran. A total of 1225 individuals were randomly recruited for the study. As some questions in the questionnaires were unanswered, the total number of persons with quality of life scores presented in tables 1 and 2 is lower. Samples from each township were determined using stratified classification. In urban and rural areas, clustered randomization was performed, some clusters were selected, and for each household, an individual aged above 40 years was tasked with completing a SF-36 questionnaire and a questionnaire of satisfaction with lifestyle and inclination for modifying behavior and socioeconomic and demographic variables.

SF-36 is a standard questionnaire with 36 items in 8 scales. The reliability and validity of the questionnaire has been confirmed in different societies $(1,6,9)$. The scales include General Health (GH), Physical Health (PH), Role-Physical (RP), Role-Emotional (RE), Social Function (SF), Body Pain (BP), Vital Energy (VE), and Mental Health (MH). All Likert scales were scored from 0 to 100 , with higher scores denoting better health. Once data were collected, they were analyzed on SPSS software using t-test and analysis of variance.

\section{Results}

Table 1 presents the distribution of frequency of study participants in terms of satisfaction with lifestyle, history of disease, smoking and demographic variables. The mean and standard deviation of individuals aged above 40 years was 51.5 and 10.3 years, respectively. 
Table 1. Distribution of frequency of participants in terms of satisfaction with lifestyle and demographic variables in Mazandaran

\begin{tabular}{|c|c|c|c|c|c|c|}
\hline \multicolumn{2}{|c|}{$\begin{array}{l}\text { Satisfaction with } \\
\text { lifestyle }\end{array}$} & Satisfied & Unsatisfied & Indifferent & Total & $\begin{array}{c}P \\
\text { value }\end{array}$ \\
\hline Age & $\begin{array}{l}40-49 \\
\text { years } \\
50-59 \\
\text { years } \\
60 \text { years } \\
\text { or more }\end{array}$ & $\begin{array}{l}417 \\
194 \\
130\end{array}$ & $\begin{array}{l}60 \\
46 \\
39\end{array}$ & $\begin{array}{l}131 \\
81 \\
63\end{array}$ & $\begin{array}{l}608 \\
321 \\
232\end{array}$ & $<0.004$ \\
\hline Residence & $\begin{array}{l}\text { Urban } \\
\text { Rural }\end{array}$ & $\begin{array}{l}422 \\
333 \\
\end{array}$ & $\begin{array}{l}58 \\
89 \\
\end{array}$ & $\begin{array}{l}113 \\
173 \\
\end{array}$ & $\begin{array}{l}593 \\
595 \\
\end{array}$ & $<0.001$ \\
\hline Sex & $\begin{array}{l}\text { Female } \\
\text { Male }\end{array}$ & $\begin{array}{l}371 \\
385 \\
\end{array}$ & $\begin{array}{l}84 \\
65 \\
\end{array}$ & $\begin{array}{l}110 \\
167 \\
\end{array}$ & $\begin{array}{l}565 \\
617 \\
\end{array}$ & $<0.002$ \\
\hline $\begin{array}{l}\text { History } \\
\text { of disease }\end{array}$ & $\begin{array}{l}\text { Mentioned } \\
\text { Not } \\
\text { mentioned }\end{array}$ & $\begin{array}{l}313 \\
409\end{array}$ & $\begin{array}{l}97 \\
41\end{array}$ & $\begin{array}{l}145 \\
128\end{array}$ & $\begin{array}{l}555 \\
578\end{array}$ & $<0.001$ \\
\hline $\begin{array}{l}\text { Marital } \\
\text { status }\end{array}$ & $\begin{array}{l}\text { Single } \\
\text { Married } \\
\text { Widowed, } \\
\text { divorced }\end{array}$ & $\begin{array}{c}23 \\
684 \\
48\end{array}$ & $\begin{array}{c}3 \\
118 \\
25\end{array}$ & $\begin{array}{c}5 \\
244 \\
35\end{array}$ & $\begin{array}{c}31 \\
1046 \\
108\end{array}$ & $<0.001$ \\
\hline $\begin{array}{l}\text { Tobacco } \\
\text { use }\end{array}$ & $\begin{array}{l}\text { Positive } \\
\text { Negative }\end{array}$ & $\begin{array}{l}595 \\
146 \\
\end{array}$ & $\begin{array}{c}100 \\
41\end{array}$ & $\begin{array}{c}197 \\
81 \\
\end{array}$ & $\begin{array}{l}892 \\
268 \\
\end{array}$ & $<0.001$ \\
\hline
\end{tabular}

People residing in cities were more satisfied with their lifestyle compared to those in rural area, and the difference was significant $(\mathrm{p}<0.001)$. We also observed a significant relationship between satisfaction with lifestyle and sex, as women were more frequently unsatisfied with their lifestyle. A significant relationship was found between satisfaction with lifestyle and being married. Similarly, the relationship between age and satisfaction with lifestyle was significant. Among the unsatisfied respondents, illiteracy was more common $(\mathrm{p}<0.001)$. Tobacco use was another variable in the three groups. A total of 595 individuals $(80.3 \%)$ in the satisfied group did not smoke (19.7\% were smokers). However, $70.9 \%$ of those in the unsatisfied or indifferent groups were nonsmokers (i.e. $29.1 \%$ were smokers), indicating a significant difference $(\mathrm{p}<0.001)$. Table 2 provides the mean health scores of the participants for 8 scales of the SF-36 questionnaire in the three groups. The mean value of all scales was significantly related to lifestyle $(\mathrm{p}<0.001)$. Those satisfied with their lifestyle scored better in all scales compared to those who were unsatisfied, and those indifferent about their lifestyle (making no comment) were between the two other groups in terms of quality of life scores. The same pattern is observed for all scales. Similarly, the Physical Component Summary (PCS) and Mental Component Summary (MCS) measures were different in the three groups $(\mathrm{p}<0.001)$.
Table 2. Mean scores of quality of life for satisfaction with lifestyle in Mazandaran

\begin{tabular}{|c|c|c|c|c|}
\hline $\begin{array}{c}\text { Satisfaction with } \\
\text { lifestyle } \\
\text { Item of quality of } \\
\text { life }\end{array}$ & $\begin{array}{c}\text { Satisfied } \\
\mathbf{N = 7 6 2}\end{array}$ & $\begin{array}{c}\text { Unsatisfied } \\
\mathbf{N = 1 4 9}\end{array}$ & $\begin{array}{c}\text { Indifferent } \\
\mathbf{N}=\mathbf{2 8 3}\end{array}$ & $\mathbf{P}$ value \\
\hline General Health & 66.7 & 25.4 & 58 & $<0.001$ \\
\hline Physical Health & 73.5 & 63.8 & 66.2 & $<0.001$ \\
\hline Role Physical & 63.8 & 53.8 & 54.4 & $<0.001$ \\
\hline Role Emotional & 62.8 & 59.3 & 53.8 & $<0.004$ \\
\hline Body Pain & 66.7 & 53.9 & 62.8 & $<0.001$ \\
\hline Social Function & 67.5 & 56.1 & 60.8 & $<0.001$ \\
\hline Vital Energy & 62.8 & 47.1 & 56 & $<0.001$ \\
\hline Mental Health & 68.2 & 55.2 & 59.2 & $<0.001$ \\
\hline $\begin{array}{c}\text { Mental } \\
\text { Component } \\
\text { Summary }\end{array}$ & 58.2 & 30 & 42.6 & $<0.001$ \\
\hline $\begin{array}{c}\text { Physical } \\
\text { Component } \\
\text { Summary }\end{array}$ & 55.1 & 39.5 & 44.5 & $<0.001$ \\
\hline
\end{tabular}

Table 3 demonstrates that the inclination to modify behavior is significantly related to satisfaction with lifestyle, although the types of behaviors they wish to change differ. Satisfied individuals have better quality of life tend to focus on exercise and nutrition, whereas those who were unsatisfied or indifferent showed interest in stress control alongside nutrition and exercise. The inclination to exercise, quit smoking, and control stress was significantly different among the three groups.

Table 3. Distribution of frequency of inclination to modify behavior and satisfaction with lifestyle

\begin{tabular}{|l|c|c|c|c|}
\hline \multicolumn{1}{|c|}{ Lifestyle } & Satisfied & Unsatisfied & Indifferent & $\begin{array}{c}\text { P } \\
\text { value } \\
\text { Mehavior to change }\end{array}$ \\
\hline Exercise & $\begin{array}{c}324 \\
(42.5)\end{array}$ & $40(26.8)$ & $103(35.9)$ & 0.001 \\
\hline Nutrition & $\begin{array}{c}304 \\
(39.9)\end{array}$ & $66(44.3)$ & $106(36.9)$ & 0.326 \\
\hline Weight control & $\begin{array}{c}164 \\
(21.5)\end{array}$ & $22(14.8)$ & $58(20.2)$ & 0.173 \\
\hline Quitting smoking & $55(7.2)$ & $23(15.4)$ & $30(10.5)$ & 0.004 \\
\hline Stress control & $\begin{array}{c}214 \\
(28.1)\end{array}$ & $71(47.7)$ & $77(26.8)$ & 0.001 \\
\hline Other behaviors & $90(11.8)$ & $27(18.1)$ & $39(13.6)$ & 0.106 \\
\hline
\end{tabular}




\section{Discussion}

According to the findings of our study, all scales of quality of life and the summary measures physical and mental components are related to satisfaction with lifestyle. Individuals unsatisfied with or indifferent towards their lifestyle had lower health scores. This has been previously indicated in several studies (3-5). Another finding of our study is that people who were unsatisfied with or indifferent towards their lifestyle were inclined to different behavior modifications, most particularly quitting smoking, controlling stress and losing weight, which is consistent with many studies which indicated the relationship between smoking and quality of life (10-12). A study by Martinez et al on Brazilian students suggested that all items of quality of life in SF-36 are lower in healthy students who smoked (lightly or heavily) compared to those who did not (10). Tillmann et al in Scotland demonstrated significant differences in 5 out of 8 scales of SF-36 between those who smoked and those who smoked for more than 5 years (11). Similarly in our study, the quality of life was higher in nonsmokers, and the smokers mentioned that quitting smoking is one of the changes they would like to accomplish. Toobert et al reported the Mediterranean lifestyle with its low saturated fat diet to improve the quality of life (12).

Those satisfied with their lifestyle have better quality of life, and among the different behavior they wish to modify, nutrition and exercise are the most important, which is in line with numerous studies which corroborate the relationship between nutrition and physical activity on quality of life (SF-36) $(3,4)$. Jennifer et al conducted a cohort study in 1992 on 40098 women aged 46-71 years, indicating that their weight changes are related to items of SF-36, especially the physical items (13). Chaoyang et al. clustered the habits of lifestyle and studied their relationship to quality of life in 16428 American patients.
They considered $0,1,2$ and 3 multiple healthrelated habits including not smoking, physical exercise, and consuming 5 times or more fruit and vegetables, and demonstrated that increasing multiple behaviors will raise the mental and physical quality of life (3). Other studies also confirm the relationship between an active lifestyle and quality of life (4) and between history of disease and quality of life (15). In our study, participants who reported a history of disease had lower quality of life.

Therefore, better quality of life is associated with satisfaction with lifestyle, and the pattern of inclination towards modifying behavior tends towards nutrition and exercise. Dissatisfaction with lifestyle and low quality of life encourage behavior modification in tobacco use, weight changes and stress control. As we demonstrated the impact of age, sex, residence, history of disease, marital status, smoking, and education level on satisfaction with lifestyle and quality of life scores, we recommend the acquisition of necessary education in order to provide models for correct behavior so that it may improve healthrelated quality of life.

\section{Acknowledgements}

We thank our colleagues in Deputy of Research at the university and all experts and contributors to the study. The present article is the result of a university research project under registration number 82-116. 


\section{References}

1. Ware J.E and Gandek B. Overview of the SF-36 health survey and the international Quality of life assessment (IQOLA) project.J. Clin. Epidemiol. 1998; 51(11): 903-912.

2. Cassidy k, Kotynia. English R, Acres J, Flicker L, LautenseChlager NT and Almedia OP. Association between lifestyle factors and mental health measures among community- dwelling older woman. Australian and New Zealand Journal of Psychiatry 2004; 38:940-947.

3. Chaoyang Li C, Ford ES, Mokdad AH, Jiles R and Giles WH., clustering of multiple healthy lifestyle habits and health- related quality of life among U.S. adults with diabetes. Diabetes Care,July 2007; 30(7): 1770-1776.

4. Al-Mandhari AS, Hassan AA and Haran D. Association between perceived health status and satisfaction with quality of care: evidence from users of primary health care in Oman. Family Practice 2004; 21: 519527.

5. Schwartz C, Meisenhelder JB, Yunsheng RN and Reed G. Altruistic Social Interest Behaviors Are Associated With Better Mental Health. Psychosomatic Medicine 2003; 65:778-785.

6. Gashtasbi A, Montazeri A, Vahdania S, Rahimi A, Mohammad K. Assessment of the health in people of Tehran based on sex, education, region of residence, a population-based study. Payeshquartery, 2th, 2003; No; 3:183-189.

7. NorbalaA,Mohammad K. National plan of health Study and Illness in Iran. National Research Center of Medical Sciences Report, Ministry of Health and Medical Education, Tehran, 2000.
8. Habibi S, Nikpour S, Seyedoshhadaii M, Haqqani $H$. assessment of promotion behaviors and quality of life of the elderly. Journal of Ardabil University of Medical Sciences. 2008; 8(2): 63-29.

9. Mohammadpour R.A and Yousefi Z., Factor analysis of SF-36 Persian version health-related quality of life questionnaire in Iran, World Applied Sciences journal, 2008; 3(4): 548-554.

10. Martinez BJ A, Mota GA, Vianna E SO, Filho JT. Silva GA and Rodriguez AL Jr. Impaired quality of life of healthy young smokers, chest, February 2004; 125(2):425-428.

11. Tillmann M and Silcock J. A comparison of smokers' and ex-smokers' health-related quality of life. Journal of Public Health Medicine, 1999; 19(3): 268-273.

12. Toobert DJ. Glasgow RE. Strycker LA. Barrerra M JR. Radcliffe JL. Wander RC. And Bagdade JD. Biologic and quality of life outcomes from the Mediterranean lifestyle program; a randomized clinical trial. Diabetes Care,August 2003; 26(8): 2288-2293.

13. Fine JT. Colditz GA. Coakly EH. Moseley G. Manson JE. Willett Wc. And Kawachi I. A perspective study of weight change and health- related quality of life in women. IAMA, 1999; 282: 2136-2142.

14. Peterson JJ, Lowe JB, Peterson NA and Janz KF. The relationship between active living and health-related quality of life: income as a moderator. Health Education Research, Theory \& practice,2006; 21(1): 146-156.

15. Cindy LK Lam, Ian J Lauder and Tai-pong D Lam, Impact of chronic diseases on health services and quality of life of a Chinese population, Asia pacific Family Medicine, 2003; 2:98-106. 